\title{
Drug-likeness of Phytic Acid and Its Analogues
}

\author{
Amitha Joy ${ }^{1,2}$ and S. Balaji ${ }^{*}, 3$
}

${ }^{I}$ Department of Biotechnology, Sahrdaya College of Engineering and Technology, Kodakara-680684, Thrissur, India; ${ }^{2} R \& D$ Centre, Bharathiar University, Coimbatore, Tamilnadu, 641046, India; ${ }^{3}$ Department of Biotechnology, Manipal Institute of Technology, Manipal 576104, Karnataka, India

\begin{abstract}
Inositol hexakisphosphate is known to be the phosphorous reserve in plants particularly in the seeds. Though it has been known for its antinutrient properties for many years, recent research shed light to reveal it as a novel anticancer agent. Hence the present study investigates the drug-likeness of phytic acid and its analogues through bioinformatics methods. Two potential cancer drug targets such as mitogen activated kinase and inositol 1,4,5-triphosphate receptor are included in the study. Out of 50 selected analogues of phytic acid, 42 structures interact well with the chosen drug targets. The best interacting structures are 1-diphosinositol pentakisphosphate and 2,3,4,5,6-pentaphosphonooxycyclohexyl dihydrogen phosphate. For both of these structures, the negative binding energy obtained was $-49.5 \mathrm{KJ} / \mathrm{mol}$; this affirms the stability of the complex. ADME properties are also predicted to assess the drug-like properties of the compounds. The structure activity relationship model is generated for 12 compounds with experimental $\mathrm{IC}_{50}$ values.
\end{abstract}

Keywords: Analogues, binding energy, bioactivity, docking, druglikeness, phytic acid.

\section{INTRODUCTION}

Inositol hexakisphosphate (InsP6), also known as phytic acid is the foremost inositol phosphate discovered [1]. It is the most abundant organic phosphate in the world [2]. In plants, InsP6 acts as a phosphate reserve, especially in the seeds [3]. In nature phytic acid $\left(\mathrm{C}_{6} \mathrm{H}_{18} \mathrm{O}_{24} \mathrm{P}_{6}\right)$ can exist as free acid, phytate or phytin, depending on the physiological $\mathrm{pH}$ and metal salts [4]. The percentage of phytate in many of the plants has been quantified [5] and their antinutrient properties are well studied [6]. Recent research investigations have demonstrated its activity against cancer cell lines such as human colon cancer cell line (HT-29), erythroleukemic cell line (K-562), human liver cancer cell line (HepG2), human prostate carcinoma cell line (DU 145) and rhabdomyosarcoma cell line (RD) $[7,8]$. The pessimistic view of phytic acid in human diet is optimistically assigned for human health due to its anti-cancer activities in colon, prostate, metastatic and breast cancers. It is also used to chelate and clear renal stones [9]. Besides in vitro studies, the in vivo studies using animal models support anticancer effects of phytic acid and hence phytic acid is referred to as 'natural cancer fighter' [10]. However the drug-likeness of phytic acid is not well documented in literature, some more research investigations and clinical trials need to be done to prove its drug-likeness. Computational methods play a vital role in the screening of lead molecules, designing novel drug molecules, identifying potent protein targets and also to understand the mechanism of drug action in greater detail. In particular docking and QSAR studies are effective for understanding the structural features of lead molecules. In silico approaches can assist

*Address correspondence to this author at the Department of Biotechnology, Manipal Institute of Technology, Manipal 576104, Karnataka, India;

E-mails: biobalagi@gmail.com; s.balaji@manipal.edu in this regard to study the interactions of phytic acid with various drug targets. At present there is no published research work on the structure-activity relationship (SAR) of phytic acid and its analogues. Elucidating SAR can help in screening out novel inhibitors that can bind with the druggable targets. Hence the present study makes an attempt to bring forth the drug-like properties of phytic acid and its analogues through computational approach.

\section{METHODOLOGY}

\subsection{Ligand Preparation}

The 2D structures of phytic acid and its analogues were retrieved from the Pubchem repository of NCBI [11]. Ligprep module [12] was used to prepare ligands. It employed series of steps that performed 3D conversions, corrections and optimization of the following structures. The Pubchem accession numbers are given below

$\begin{array}{lll}\text { CID477, CID890, } & \text { CID107758, } & \text { CID125004, } \\ \text { CID127297, } & \text { CID178749, } & \text { CID439456, } \\ \text { CID443266, } & \text { CID2524165, } & \text { CID4200706, } \\ \text { CID4487899, } & \text { CID10251645, } & \text { CID10747577, } \\ \text { CID14375662, } & \text { CID16752671, } & \text { CID16752673, } \\ \text { CID18365880, } & \text { CID21099914, } & \text { CID44274820, } \\ \text { CID44332437, } & \text { CID45479488, } & \text { CID46173206, } \\ \text { CID46173281, } & \text { CID46173316, } & \text { CID46173429, } \\ \text { CID46173525, } & \text { CID46905360, } & \text { CID52949527, } \\ \text { CID53379838, } & \text { CID53380009, } & \text { CID53380097, } \\ \text { CID53380098, } & \text { CID53380099, } & \text { CID53380100, } \\ \text { CID53380197, } & \text { CID53380199, } & \text { CID53380200, } \\ \text { CID53380300, } & \text { CID53380301, } & \text { CID53380721, } \\ \text { CID53380834, } & \text { CID53380835, } & \text { CID53380836, } \\ \text { CID53380837, } & \text { CID53462026, } & \text { CID53477671, } \\ \text { CID54002314, } & \text { CID54207372, } & \text { CID57503246 }\end{array}$
CID125004 CID439456, CID4200706, CID10747577, CID16752673, CID44274820 CID46173206, CID52949527, CID53380097, CID53380100, CID53380200, CID53380836, CID57503246 


\subsection{Identification and Preparation of Protein Targets}

Identification of a protein target is a crucial step in interaction studies. In the present work one such target was selected using PASS online server [13]. The server predicts several pharmacological effects and biochemical mechanisms on the basis of structural formula of a substance. The prediction results are analyzed based on the activity values. The compound is very likely to reveal the activity in experimentation if the activity value $>0.7$. If the compound is between 0.5 and 0.7 it is expected to exhibit the activity in experiment but the likelihood is less. The substance is improbable to display the activity in experiment if the activity value is $<0.5$. Based on the PASS results Inositol 1,4,5-triphosphate receptor was selected as a protein target. Literature survey suggested one more potent drug target for colon cancer mitogen activated protein kinase $[14,15]$. Their corresponding PDB ids 1N4K and 1PMQ were chosen for the study. The crystal structures of the two receptors were prepared using Proteinprep wizard of Schrödinger Release 2013-1 [16]. The PDB file included a co-crystallized ligand and does not include explicit hydrogens. The structures were prepared by adding hydrogens appropriately to get refined structures.

\subsection{Grid Generation and Docking}

Grid generation was done using the Glide module of Schrödinger Release 2013-1 [17]. The ligand poses produced are subjected to move across a chain of ranked screens that estimate the ligand's interaction with the receptor. In grid generation, pose refers to a whole measurement of the ligand location and orientation relative to the receptor core conformation as well as rotamer set conformations. Receptor atom van der Waals radii can be scaled and either partial charges from the force field or from the input structure can be chosen. The maximum size of the enclosing grid box was set as $50 \AA$. The process of docking a ligand into a binding site tries to generate low energy conformations. The molecules are brought together by assigning planes that contain the sites of interaction and then moving the planes while calculating binding energies of interaction [18]. Here docking was done using Glide module. Glide uses a series of hierarchical filters to search for possible locations of the ligand in the active-site region of the receptor. The shape and properties of the receptor are represented on a grid by different sets of fields that provide progressively more accurate scoring of the ligand poses [19].

\subsection{Prime MM-GBSA}

The ligand binding energies were calculated using molecular mechanics with generalized Born and surface area solvation (Prime MM-GBSA) [20]. Combinations of the docking method with other methods, such as MD simulation and free energy binding calculation enables rational drug design [21]. Solvation plays an important role in molecular recognition that was considered in the MM-GBSA scoring [22]. Prime MM-GBSA predicts various energies of the complex such as coulomb energy, covalent binding energy, van der Waals energy, surface area, solvation energy, prime energy, mmgbsa energy, mmgbsa energy of the free ligand, mmgbsa energy of the uncomplexed receptor, mmgbsa energy of the ligand in the complex, mmgbsa ligand strain energy and mmgbsa free energy of binding excluding ligand strain.

\subsection{Computational Prediction of ADME Properties}

Absorption, distribution, metabolism, and excretion (ADME) properties of phytic acid and its derivatives were predicted by QuikProp [23]. QuikProp also predicts physically significant descriptors and pharmaceutically relevant properties for organic structures, either individually or in batches. The QuikProp predictions are for orally delivered drugs and for non-active transport. It also checks the Lipinski's rule of five [24].

\subsection{QSAR Studies}

Quantitative structure activity relationship of phytic acid and its derivatives were predicted by using GUSAR software. It helps to create QSAR models on the basis of the appropriate training sets [25]. It used a self-consistent regression (a regularized least-squares method) for building QSAR models [26]. Out of the 50 structures, 12 were selected for the studies for which the experimental $\mathrm{IC}_{50}$ values were available in Pubchem database. Based on the training set, $\mathrm{IC}_{50}$ values were predicted using quantitative neighbourhood of atoms (QNA model) and multilevel neighbourhood of atoms (MNA model) [27]. On the basis of QNA descriptors the involvement of every atom corresponding to its experimental activity is displayed. The predicted value correlates with the activity of the whole molecule is indicated by green, blue implies that the predicted value is below the activity of the whole molecule and red indicates that the predicted value is greater than that of the whole molecule.

\section{RESULTS AND DISCUSSION}

The structure of phytic acid was very likely to be active against 46 targets, Table 1. It is instinctive as well as evident that phytic acid is an inositol 1,4,5-triphosphate receptor 1 antagonist. This is in concord with Sakakura et al., they suggested inositol 1,4,5-triphosphate receptor as a molecular target for gastric cancers [28]. The crystal structure of inositol 1,4,5-triphosphate receptor in complex with $\mathrm{IP}_{3}$ is available in PDB (1N4K). Inositol 1,4,5-triphosphate receptor is involved in calcium signalling process. Calcium signaling is a vibrant signalling pathway which regulates numerous cellular processes, including fertilization, cell growth, transformation, secretion, smooth muscle contraction, sensory perception and neuronal signaling [29]. Binding in the IP3 receptor therefore affects the calcium signalling pathway. MAPKs (Mitogen activated kinases) are involved in directing cellular responses to a diverse array of stimuli. They regulate cell functions including proliferation, gene expression, differentiation, mitosis, cell survival, and apoptosis [30]. There are several cancer drugs which target on MAPKs [31,32]. 
Table 1. Predicted biological activity spectrum of phytic acid.

\begin{tabular}{|l|l|l|l|}
\hline SI No. & $\mathbf{P a}$ & $\mathbf{P i}$ & Activity \\
\hline \hline 1 & 0,986 & 0,000 & Inositol 1,4,5-triphosphate receptor 1 antagonist \\
\hline 2 & 0,981 & 0,002 & Tubulin antagonist \\
\hline 3 & 0,959 & 0,003 & Angiogenesis inhibitor \\
\hline 4 & 0,954 & 0,000 & Sphingosine 1-phosphate receptor 5 antagonist \\
\hline 5 & 0,909 & 0,004 & Sugar-phosphatase inhibitor \\
\hline 6 & 0,904 & 0,003 & Bisphosphoglycerate phosphatase inhibitor \\
\hline 7 & 0,897 & 0,009 & Aspulvinonedimethylallyltransferase inhibitor \\
\hline 8 & 0,882 & 0,003 & Ribulose-phosphate 3-epimerase inhibitor \\
\hline 9 & 0,859 & 0,007 & Mannotetraose 2-alpha-N-acetylglucosaminyltransferase inhibitor \\
\hline 10 & 0,818 & 0,010 & Glucose oxidase inhibitor \\
\hline
\end{tabular}

Pa- probability to be active; Pi- probability to be inactive.

\subsection{Docking Results}

Docking was carried out using phytic acid and its analogues using the targets, $1 \mathrm{~N} 4 \mathrm{~K}$ and $1 \mathrm{PMQ}$. The results show that all the selected compounds effectively bind with the selected targets. 1-diphosphoinositol pentakisphosphate (46173525) gave the best docking score of -14.29 for $1 \mathrm{PMQ}$ and 2,3,4,5,6-pentaphosphonooxycyclohexyl dihydrogen phosphate (178749) gave the best docking score of -14.02 for $1 \mathrm{~N} 4 \mathrm{~K}$. Table 2 and Table $\mathbf{3}$ show the top ten docked poses. Out of fifty compounds, for 1PMQ forty two gave docking scores less than -10 and for $1 \mathrm{~N} 4 \mathrm{~K}$ forty scored less than -10 which shows both the protein targets have good binding affinity towards the selected compounds. All the ligands which scored less than -10 have hydrogen bond donor atom count ranging from 8 to 14 , hydrogen bond acceptor atom count ranging from 12 to 30 and heavy atom count ranging from 24 to 44 according to Pubchem repository [11]. These features would have influenced the binding affinity of the ligands. All the poor binders have defined and undefined steriocentred atom count ranging from 4 to 6 . This sterioisomerism also would have been responsible for their poor binding affinity. Stereochemistry in drug action is of great importance in medical practice [33]. Chiral drugs have two structurally similar forms that can act in a different way in biological systems owing to their different shapes in 3-dimensional space. In a chiral environment, one enantiomer may exhibit different chemical and pharmacological behavior than the other enantiomer and the difference in 3-dimensional structure of the inactive enantiomer prevents them from having a biological effect at this binding site [34]. This explains the impact of stereoisomerism on binding affinity.

The amino acids involved in the binding site of $1 \mathrm{~N} 4 \mathrm{~K}$ include tyrosine 567, arginine 511, arginine 265 , lysine 508 , arginine 269, glycine 268, lysine 569, arginine 568 and threonine 267. The amino acids involved in the binding site

Table 2. Docked ligands in the order of XP score (1N4K).

\begin{tabular}{|c|c|c|c|c|c|c|}
\hline Pubchemid & SP score & XP score & Emodel & Glide energy & Evdw & -27.11 \\
\hline \hline 178749 & -14.00 & -14.02 & -55.19 & -101.78 & -4.36 & -103.71 \\
\hline 4200706 & -12.47 & -12.50 & -38.07 & -83.45 & -25.11 & -73.01 \\
\hline 16752671 & -11.79 & -12.46 & 10000.00 & -47.57 & -4.36 & -32.28 \\
\hline 46173525 & -11.68 & -12.36 & 10000.00 & -43.96 & -10.61 & -63.20 \\
\hline 46173281 & -11.68 & -12.36 & 10000.00 & -43.96 & -73.76 \\
\hline 107758 & -11.51 & -12.22 & -116.22 & -80.52 & -25.73 & -14.24 \\
\hline 21099914 & -12.19 & -12.21 & 10000.00 & -49.63 & -51.18 \\
\hline 890 & -11.93 & -11.96 & 10000.00 & -63.94 & -67.45 \\
\hline 57773931 & -11.14 & -11.83 & -43.24 & -85.29 & -71 & -79.26 \\
\hline 53380198 & -11.77 & -11.80 & 10000.00 & -29.84 & -75.00 \\
\hline
\end{tabular}

SP- Single precision, XP- extra precision, Emodel- weighting of forcefield components, Evdw- vander waal's energy, Ecoul- coulombic energy. 
Table 3. Docked ligands in the order of XP score (1PMQ).

\begin{tabular}{|c|c|c|c|c|c|c|}
\hline Pubchemid & SPscore & XP score & Emodel & Glide energy & Evdw & Ecoul \\
\hline 46173525 & -5.27 & -14.29 & -79.45 & -58.95 & -19.44 & -39.51 \\
\hline 4487899 & -6.41 & -12.98 & -95.79 & -81.79 & -20.02 & -61.77 \\
\hline 53379838 & -7.11 & -12.77 & -73.91 & -84.42 & -27.11 & -57.31 \\
\hline 477 & -5.8 & -12.4 & -82.29 & -64.78 & -25.11 & -39.67 \\
\hline 125004 & -5.47 & -12.32 & -68.41 & -68.04 & -4.36 & -63.68 \\
\hline 45479488 & -5.64 & -11.99 & -82.29 & -64.78 & -25.11 & -39.67 \\
\hline 53477671 & -5.86 & -11.95 & -89.23 & -72.58 & -10.09 & -62.50 \\
\hline
\end{tabular}

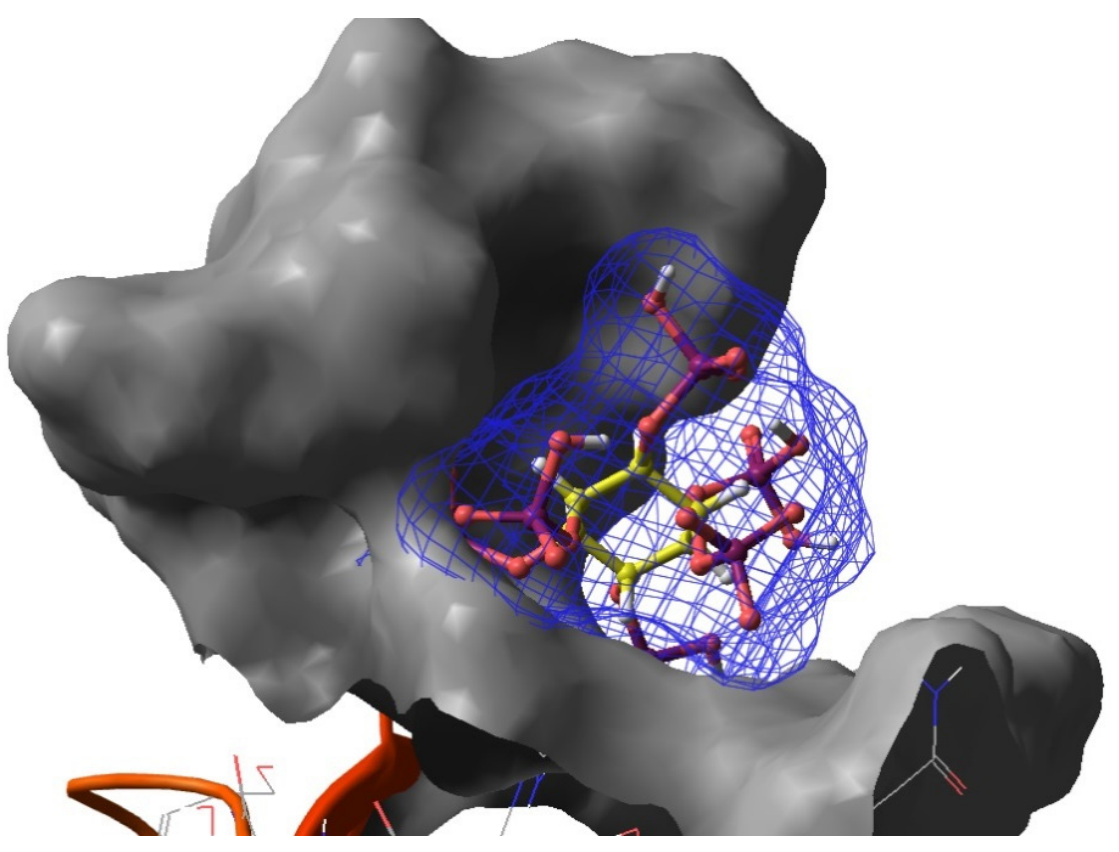

Fig. (1). Interaction of phytic acid (sticks with a mesh surface) with the binding site of the receptor 1PMQ (solid surface), rendered using Maestro (a product of Schrödinger, Inc. [16]).

of 1PMQ include lysine 93, tyrosine 223, lysine 191, valine 225 , glutamine 255 , alanine 74 , aspartate 189 , valine 224 , arginine 107 , threonine 226 , serine 193 , serine 72 , glycine 71 , valine 78 and aspargine 194. The amino acids in the binding pocket of both the proteins have some residues in common, like tyrosine, arginine, threonine, lysine and glycine. Glide scoring function is given by the equation XP GlideScore $=$ Ecoul + EvdW + Ebind + Epenalty $[35,36]$ where XP refers to the extra precision mode, its scoring function is given by the sum of the coulombic interaction energy, van der Waals energy, binding energy and penalty which includes factors that hinders binding. A pictorical representation of the interaction between phytic acid and 1PMQ receptor Fig. (1).

\subsection{MMGBSA Prediction}

The result of Prime MMGBSA distinguishes strong and weak binders (Table 4). The free energy of binding was least for (1r,2R,3S,4ss,5R,6S)-2,3,4,5,6-pentakis (phosphonooxy) cyclohexyl tetrahydrogen triphosphate (53477671). This ligand has 8 phosphate groups available for binding when compared with others. It also pocess maximum numbers of hydrogen bond donor atom count, acceptor atom count, heavy atom count and complexity values of 14, 30, 44 and 1340 respectively [11] when compared with the other ligands. The coulombic energy of the compound $\left(-38.8 \mathrm{kcalmol}^{-1}\right)$, van-der-waal's energy (-40.1 kcalmol $\left.{ }^{-1}\right)$, co-valent energy $\left(-21.6 \mathrm{kcalmol}^{-1}\right)$, coulombic binding energy (-11092.4 $\left.\mathrm{kcalmol}^{-1}\right)$ and solvation binding energy 
Table 4. MM-GBSA prediction.

\begin{tabular}{|c|c|c|c|c|c|c|}
\hline Pubchemid & $\begin{array}{c}\text { Binding Free } \\
\text { Energy } \\
\left(\text { kcalmol }^{-1}\right)\end{array}$ & $\begin{array}{l}\text { Coulombic } \\
\text { Energy of } \\
\text { Complex } \\
\left(\text { kcalmol }^{-1}\right)\end{array}$ & $\begin{array}{c}\text { Van der Waals } \\
\text { Energy of the } \\
\text { Complex }\left(\mathrm{kcalmol}^{-1}\right)\end{array}$ & $\begin{array}{c}\text { Covalent } \\
\text { Energy } \\
\left(\text { kcalmol }^{-1}\right)\end{array}$ & $\begin{array}{c}\text { Coulombic } \\
\text { Binding Energy } \\
\left(\mathrm{kcalmol}^{-1}\right)\end{array}$ & $\begin{array}{c}\text { Solvation Binding } \\
\text { Energy } \\
\left(\mathrm{kcalmol}^{-1}\right)\end{array}$ \\
\hline 53477671 & -49.5 & -38.8 & -40.1 & -21.6 & -11092.4 & -2168.6 \\
\hline 53380834 & -44.6 & -51.4 & -36.2 & 7.0 & -10964.1 & -2146.9 \\
\hline 53380100 & -37.0 & -16.4 & -49.9 & -13.2 & -10985 & -2161.7 \\
\hline 53380199 & -34.5 & -15.0 & -35.7 & -12.4 & -10958.1 & -2195.5 \\
\hline 53380835 & -33.4 & -2.4 & -42.7 & 4.1 & -10912.6 & -2184.5 \\
\hline 46173525 & -30.1 & -16.2 & -37.7 & -12.6 & -11022.8 & -2193.3 \\
\hline 53380300 & -22.2 & -26.3 & -31.0 & -10.2 & -10974.4 & -2172.3 \\
\hline 53380836 & -21.6 & -33.6 & -36.9 & 3.6 & -10952.3 & -2152.5 \\
\hline 53380098 & -21.2 & -21.5 & -41.1 & -5.9 & -10984.4 & -2152.3 \\
\hline 53380198 & -19.0 & -46.5 & -46.7 & -5.8 & -10923.2 & -2127.8 \\
\hline 53380097 & -18.3 & -3.3 & -51.8 & -12.0 & -10970.7 & -2162.9 \\
\hline 4487899 & -17.1 & -17.3 & -32.9 & -16.7 & -11037.6 & -2180.2 \\
\hline 53379838 & -16.3 & -27.3 & -35.3 & -12.9 & -11064 & -2180.0 \\
\hline 178749 & -12.8 & 7.8 & -36.5 & -21.5 & -10976.9 & -2207.2 \\
\hline 46173206 & -12.0 & -22.4 & -21.4 & -21.2 & -11037.2 & -2184.6 \\
\hline 46173429 & -10.0 & -14.2 & -19.6 & -16.7 & -11070.1 & -2172.9 \\
\hline 53380200 & -9.1 & 14.4 & -47.7 & -7.3 & -10940.1 & -2181.8 \\
\hline 53380099 & -8.8 & 8.0 & -37.7 & -1.4 & -10967.2 & -2171.5 \\
\hline 46173281 & -8.6 & -17.4 & -22.9 & -26.4 & -11030.5 & -2183.0 \\
\hline 52949527 & -6.8 & 4.1 & -25.5 & -19.3 & -11021.6 & -2196.5 \\
\hline 23675791 & -5.8 & 9.7 & -35.5 & -21.7 & -10969.9 & -2206.7 \\
\hline 10747577 & -5.7 & -21.4 & -17.0 & -13.5 & -11041.8 & -2187.5 \\
\hline 16752673 & -2.5 & -5.5 & -32.1 & -14.4 & -11018.8 & -2177.1 \\
\hline
\end{tabular}

$\left(-2168.6 \mathrm{kcalmol}^{-1}\right)$ were also significantly low. The presence of aromatic group and hydroxyl group bearing tyrosine, phosphate anion binder arginine and highly reactive amino group bearing lysine in the binding pocket of both the targets also account for the binding efficacy and binding energy minima [37]. The compound 2,3,4,5,6-pentaphosphonooxycyclohexyl dihydrogen phosphate (CID178749) ranked in the top docked poses in both the protein targets have a satisfactory binding energy minima of $-12.8 \mathrm{kcal}$ $\mathrm{mol}^{-1}$. This compound is otherwise known as technetium- 
Table 5. ADME properties prediction.

\begin{tabular}{|c|c|c|c|c|c|c|c|c|c|}
\hline Pubchem id & Molwt & SASA & FOSA & FISA & QPlogBB & Volume & DonorHB \$ & AccptHB \$ & QPlogPo/w \\
\hline 890 & 660.0 & 659.2 & 22.1 & 616.2 & -6.3 & 1279.9 & 12 & 30 & -1.6 \\
\hline 46173525 & 740.0 & 709.2 & 14.7 & 675.3 & -6.3 & 1401.3 & 10 & 32 & -1.7 \\
\hline 107758 & 500.1 & 598.6 & 38.8 & 545.5 & -7.2 & 1072.8 & 10 & 23.4 & -2.2 \\
\hline 4487899 & 740.0 & 720.8 & 24.4 & 673.3 & -5.8 & 1407.8 & 10 & 32 & -1.7 \\
\hline 45479488 & 820.0 & 750.4 & 21.9 & 701.9 & -7.2 & 1506.0 & 8 & 34 & -1.7 \\
\hline 16752671 & 740.0 & 740.5 & 5.6 & 712.5 & -6.3 & 1436.9 & 10 & 32 & -2.0 \\
\hline 16752673 & 740.0 & 695.8 & 16.7 & 659.2 & -6.1 & 1383.7 & 10 & 32 & -1.6 \\
\hline 46173525 & 740.0 & 709.2 & 14.7 & 675.3 & -6.2 & 1401.3 & 10 & 32 & -1.7 \\
\hline 4200706 & 660.0 & 691.7 & 19.4 & 649.7 & -6.5 & 1301.7 & 12 & 30 & -2.0 \\
\hline 178749 & 660.0 & 650.2 & 26.8 & 605.0 & -6.4 & 1275.9 & 12 & 30 & -1.4 \\
\hline 53462026 & 820.0 & 738.7 & 16.0 & 701.2 & -6.3 & 1504.0 & 8 & 34 & -1.6 \\
\hline 10747577 & 740.0 & 728.0 & 15.7 & 693.5 & -6.1 & 1425.1 & 10 & 32 & -1.8 \\
\hline 53477671 & 820.0 & 771.7 & 38.7 & 720.7 & -6.2 & 1532.5 & 10 & 36 & -2.4 \\
\hline 53380098 & 740.0 & 729.8 & 20.0 & 692.3 & -6.5 & 1420.4 & 7 & 30.7 & -2.1 \\
\hline 53380099 & 740.0 & 757.7 & 20.9 & 717.7 & -5.6 & 1469.2 & 7 & 30.7 & -2.1 \\
\hline 53380100 & 740.0 & 723.8 & 23.0 & 673.8 & -7.3 & 1413.8 & 7 & 30.7 & -1.9 \\
\hline 53380197 & 740.0 & 703.3 & 23.9 & 658.4 & -7.7 & 1403.5 & 7 & 30.7 & -1.8 \\
\hline 53380198 & 660.0 & 668.0 & 30.2 & 615.3 & -7.9 & 1279.6 & 6 & 27.4 & -2.1 \\
\hline 53380199 & 740.0 & 781.5 & 33.6 & 729.0 & -6.9 & 1483.1 & 7 & 30.7 & -2.3 \\
\hline 53380200 & 740.0 & 687.7 & 20.7 & 648.0 & -7.2 & 1371.3 & 7 & 30.7 & -1.8 \\
\hline 53380300 & 740.0 & 689.4 & 38.1 & 630.7 & -7.1 & 1368.7 & 7 & 30.7 & -1.7 \\
\hline 53380301 & 820.0 & 702.9 & 12.5 & 675.2 & -6.1 & 1467.4 & 8 & 34 & -1.4 \\
\hline 53380097 & 740.0 & 745.2 & 42.7 & 680.3 & -7.5 & 1437.8 & 7 & 30.7 & -2.0 \\
\hline 53380009 & 740.0 & 707.6 & 28.8 & 661.5 & -7.6 & 1418.9 & 7 & 30.7 & -1.7 \\
\hline 25245165 & 820.0 & 772.7 & 6.6 & 749.1 & -8.1 & 1535.9 & 8 & 34 & -2.0 \\
\hline 127297 & 820.0 & 718.5 & 15.8 & 676.6 & -7.6 & 1470.5 & 8 & 34 & -1.5 \\
\hline 46173281 & 740.0 & 657.4 & 32.4 & 605.0 & -8.0 & 1339.4 & 10 & 32 & -1.1 \\
\hline 46173429 & 820.0 & 750.1 & 26.4 & 701.4 & -7.3 & 1495.3 & 8 & 34 & -1.8 \\
\hline 46173316 & 740.0 & 717.9 & 22.1 & 669.6 & -6.9 & 1430.3 & 10 & 32 & -1.5 \\
\hline 46173206 & 740.0 & 692.4 & 15.3 & 658.4 & -6.5 & 1387.0 & 10 & 32 & -1.5 \\
\hline 53379838 & 820.0 & 751.0 & 11.9 & 716.9 & -8.5 & 1521.3 & 8 & 34 & -1.7 \\
\hline 53380837 & 740.0 & 748.8 & 25.7 & 696.5 & -6.8 & 1457.9 & 4 & 29.4 & -2.3 \\
\hline 53380836 & 740.0 & 729.2 & 28.2 & 678.2 & -6.6 & 1429.3 & 4 & 29.4 & -2.3 \\
\hline 53380835 & 740.0 & 706.2 & 33.7 & 652.2 & -6.9 & 1387.4 & 4 & 29.4 & -2.2 \\
\hline 53380834 & 740.0 & 710.7 & 23.2 & 664.7 & -7.6 & 1412.3 & 4 & 29.4 & -2.2 \\
\hline 53380721 & 740.0 & 749.4 & 28.1 & 692.3 & -6.9 & 1428.6 & 7 & 30.7 & -2.1 \\
\hline 125004 & 740.0 & 687.7 & 20.7 & 648.0 & -8.4 & 1371.3 & 7 & 30.7 & -1.6 \\
\hline
\end{tabular}


(Table 5) contd....

\begin{tabular}{|c|c|c|c|c|c|c|c|c|c|}
\hline Pubchem id & molwt & SASA & FOSA & FISA & QPlogBB & Volume & DonorHB \$ & AccptHB \$ & QPlogPo/w \\
\hline \hline 10251645 & 740.0 & 689.4 & 38.1 & 630.7 & -7.1 & 1368.7 & 7 & 30.7 & -1.6 \\
\hline 14375662 & 820.0 & 702.9 & 12.5 & 675.2 & -6.1 & 1467.4 & 8 & 34 & -1.6 \\
\hline 44274820 & 740.0 & 745.2 & 42.7 & 680.3 & -7.8 & 1437.8 & 7 & 30.7 & -2.0 \\
\hline 44332437 & 740.0 & 707.6 & 28.8 & 661.5 & -7.1 & 1418.9 & 7 & 30.7 & -1.3 \\
\hline 443266 & 820.0 & 772.7 & 6.6 & 749.1 & -6.8 & 1535.9 & 8 & 34 & -1.7 \\
\hline 46905360 & 820.0 & 718.5 & 15.8 & 676.6 & -7.8 & 1470.5 & 8 & 34 & -1.6 \\
\hline 477 & 740.0 & 657.4 & 32.4 & 605.0 & -7.7 & 1339.4 & 10 & 32 & -1.4 \\
\hline 439456 & 820.0 & 750.1 & 26.4 & 701.4 & -7.4 & 1495.3 & 8 & 34 \\
\hline
\end{tabular}

SASA- Total solvent accessible surface area (SASA) in square angstroms using a probe with a $1.4 \AA$ radius. FOSA- Hydrophobic component of the SASA (saturated carbon and attached hydrogen). FISA- Hydrophilic component of the SASA (SASA on N, O, and H on heteroatoms). QPlogPo/w- Predicted octanol/water partition coefficient. QPlogBB -Predicted brain/blood partition coefficient. \$- Estimated number of hydrogen bonds that would be accepted by the solute from water molecules in an aqueous solution.

Table 6. Cytotoxicity prediction using QNA, MNA and Combinatorial model.

\begin{tabular}{|c|c|c|c|c|}
\hline Pubchem id & IC $_{\mathbf{5 0}}$ & pIC $_{\mathbf{5 0}}$ (QNA) & pIC $_{\mathbf{5 0}}$ (MNA) & pIC $\mathbf{5 0}$ (Combinatorial) \\
\hline \hline 477 & 0.087 & 0.44 & -3.35 & -0.15 \\
\hline 890 & 4.39 & 5.97 & -0.71 & -0.14 \\
\hline 107758 & 0.002 & 0.46 & -3.38 & 15.38 \\
\hline 125004 & 20 & 17.68 & 18.64 & 2.85 \\
\hline 439456 & 3.55 & 4.17 & -0.23 & 0.04 \\
\hline 443266 & 0.43 & 0.39 & -3.03 & -0.01 \\
\hline 10251645 & 2 & 0.95 & -7.18 & -0.01 \\
\hline 14375662 & 0.268 & 0.95 & -7.18 & 18.12 \\
\hline 16752673 & 19 & 17.89 & -27.9 & -2.08 \\
\hline 44274820 & 0.009 & -2.75 & -0.23 & 2.85 \\
\hline 44332437 & 0.28 & 4.17 & -4.32 & -0.86 \\
\hline 46905360 & 0.172 & -0.18 & \\
\hline
\end{tabular}

$\mathrm{IC}_{50}$ - experimental $\mathrm{IC}_{50}, \mathrm{p} \mathrm{IC} \mathrm{I0}_{50}$ predicted $\mathrm{IC}_{50}$

$\mathrm{N}=12, \mathrm{R} 2=0.976, \mathrm{~F}=27.059, \mathrm{SD}=1.600, \mathrm{Q} 2=0.453, \mathrm{~V}=3$

$\mathrm{N}$ is total number of molecules used, $\mathrm{R}$ is correlation coefficient, $\mathrm{F}$ is value of Fischer's parameter, SD is standard deviation, the cross-validated R2 and V is no. of variables used in the model building.

$99 \mathrm{~m}$. Technetium-99m is a radioisotope most widely used in medicine employed in over half of all nuclear medicine procedures [38].

Thirty one of the compounds gave minimum energy values. The presence of hydroxyl and phosphate functional groups in these compounds enhanced their binding affinity. The negative binding free energies showed favourable ligand protein complexes.

\subsection{ADME Screening}

According to the Qikprop analysis 44 physically significant descriptors and pharmaceutically relevant properties of the ligands like molecular weight, total solvent accessible surface area (SASA), hydrophobic and hydrophilic component and volume were obtained. The Table $\mathbf{5}$ shows some of the predicted properties. Natural products are frequently cited as exclusion to Lipinski's rules because environment has learned to sustain low hydrophobicity and intermolecular H-bond donating ability when it needs to make biologically active compounds with high molecular weight and large numbers of rotatable bonds [39].

\subsection{Quantitative Structure Activity Relationship Study Using GUSAR}

QSARs are mathematical models that attempt to relate the structure-derived features of a compound to its biological or physicochemical activity. QSAR works on the assumption that structurally similar compounds have similar activities [40]. In the present work, in the consensus QSAR model 
given by GUSAR. In the present study majority of the selected compounds correlate with experimental and predicted activity. Three models were generated by GUSARQNA model, MNA and Combinatorial model as given in Table 6. For QNA model and Combinatorial model the predicted $\mathrm{IC}_{50}$ values were very less deviated from the experimental $\mathrm{IC}_{50}$. QNA model gave $\mathrm{r}^{2}$ (goodness of fit) of 0.943 and Combinatorial model gave the best result with $r^{2}$ value 0.960 . For MNA model the $\mathrm{r}^{2}$ value is 0.660 .

The statistical characteristics of the model with high value of $\mathrm{r}^{2}, \mathrm{q}^{2}, \mathrm{~F}$ and low value of $\mathrm{SD}$ and the equation indicates that the model is statistically significant, could be used for analogue screening. The regression equations for the MNA model, QNA model and combinatorial model are $1.33 x-7.298,0.899 x+0.419$ and $0.836 x-0.303$ respectively indicates a linear relationship between experimental $\mathrm{IC}_{50}$ value and predicted $\mathrm{IC}_{50}$ value. Therefore phytic acid and the selected analogues for GUSAR studies have similar activities.

\section{CONCLUSION}

The present work identified mitogen activated kinase and inositol 1,4,5-triphosphate receptor as the protein targets for phytic acid. The interaction (docking scores) are -14.29 and -14.02, respectively. The protein ligand complexes had a minimum binding energy of $-49.5 \mathrm{~kJ} / \mathrm{mol}$. The parent compound, phytic acid and its similar compounds resemble similar mode of binding due to chemical similarity. The amino acid pattern involved in the binding interaction is almost same for all the compounds. The analyzed compounds are predicted to be drug-like. The structure activity relationship model correlated the atom level contributions to the activity. This would be made beneficial for designing novel drug compounds. Furthermore animal trials and clinical studies and can reveal more insights into the drug-likeness of phytic acid.

\section{CONFLICT OF INTEREST}

The authors declare that there are no conflicts of interest.

\section{ACKNOWLEDGEMENTS}

The authors show their sincere gratitude to the reviewers of this manuscript. They also extend their gratitude to the software provider Mr. Raghu Rangaswamy, Vice President, Schrödinger and Vinod Devaraji Junior Applications Scientist for the evaluation version and academic license.

\section{REFERENCES}

[1] Vucenik I, Shamsuddin AM. Cancer inhibition by inositol hexaphosphate (IP6) and inositol: from laboratory to clinic. J Nutr 2003; 133: 3778-84

[2] Irvine FR, Schell MJ. Back in the water: the return of the inositol phosphates. Reviews.2001; 2: 327-38.

[3] Mohammad A, Nawab A, Mariya K. Quantitative detection of inositol hexakisphosphate (InsP6) in crop plants using polyacrylamide gel electrophoresis (PAGE). American J Plant Sci 2013; 4: 1-6.

[4] George TT, Yizhou Z, Jean L, Cheng S. Gong. Absorption of Heavy metal Ions by Immobilized Phytic acid. Appl Biochem Biotechnol 1997; 63-5.
[5] Andargachew G, Admasu T, Girma A, et al. Nutrient composition and effect of processing on antinutritional factors and mineral bioavailability of cultivated amochi in Ethiopia. J Sci Develop 2011; 1: 21-9.

[6] Bohn L, Meyer AS, Rasmussen SK. Phytate: impact on environment and human nutrition. A challenge for molecular breeding. J Zhejiang Univ Sci 2008; 9: 165-91.

[7] Fox CH, Eberl M. Phytic acid (IP6), novel broad spectrum antineoplastic agent: a systematic review. Complement Ther Med 2002; 10: 229-34.

[8] Norhaizan ME, Norashareena MS, Abdah MA. Antioxidant and cytotoxicity effect of ricebranphytic acid as an anticancer agent on ovarian, breast and liver cancer cell lines. Malays J Nutr 2011; 17: 367-75.

[9] Dost K, Tokul O. Determination of phytic acid in wheat and wheat products by reverse phase high performance liquid chromatography. Anal Chim Acta 2006; 558: 22-7.

[10] Norhaizan ME, Hairuszah I, Abdah MA, et al. Rice bran phytic acid (IP6) induces growth inhibition, cell cycle arrest and apoptosis on human colorectal adenocarcinoma cells. J Med Plants Res 2010; 4(21): 2283-9.

[11] Bolton E, Wang Y, Thiessen PA, et al. PubChem: Integrated Platform of Small Molecules and Biological Activities. In: Annual Reports in Computational Chemistry, American Chemical Society: Washington 2008; p. 4.

[12] Schrödinger Release 2013-1: LigPrep, version 3.1, Schrödinger, LLC, New York, NY 2014.

[13] Lagunin A, Stepanchikova A, Filimonov D et al. Pass: prediction of activity spectra for biologically active substances. Bioinformatics 2000; 16: 747-8.

[14] Arslan, MA, Kutuk O, Basaga H. Protein kinases as drug targets in cancer.Curr Cancer Drug Targets 2006; 7: 623-34.

[15] Wawszczyk J, Orchel A, Kapral M, et al. Phytic acid downregulates IL-8 secretion from colonic Epithelial cells by influencing mitogen-activated protein Kinase signaling pathway. Acta Pol Pharm 2012; 69: 1276-82.

[16] Schrödinger Release 2013-1: Schrödinger Suite 2013 Protein Preparation Wizard; Epik version 2.4, Schrödinger, LLC, New York, NY, 2013; Impact version 5.9, Schrödinger, LLC, New York, NY, 2013; Prime version 3.2, Schrödinger, LLC, New York, NY, 2013.

[17] Schrödinger Suite 2013 QM-Polarized Ligand Docking protocol; Glide version 5.9, Schrödinger, LLC, New York, NY, 2013; Jaguar version 8.0, Schrödinger, LLC, New York, NY, 2013; QSite version 5.9, Schrödinger, LLC, New York, NY, 2013.

[18] Cohen NC. Molecular modelling in drug design. Elsevier, USA 2006.

[19] Friesner RA, Murphyv RB, Repasky MP, et al. Glide: A new approach for rapid accurate docking and scoring. 1. Method and assessment of docking accuracy. J Med Chem 2002; 47: 1739-49.

[20] Schrödinger Suite 2013-1 Induced Fit Docking protocol; Glide version 5.9, Schrödinger, LLC, New York, NY, 2013; Prime version 3.2, Schrödinger, LLC, New York, NY 2013

[21] Godschalk F, Genheden S, Söderhjelm P. Comparison of MM/ GBSA calculations based on explicit and implicit solvent simulations. Phys Chem Chem Phys 2013; 15: 7731-9.

[22] Kroeme RT. Structure-based drug design: docking and scoring. Curr Protein Pept Sci 2007; 8: 312-28.

[23] Small-Molecule Drug Discovery Suite 2013-1: QikProp, version 3.6, Schrödinger, LLC, New York, NY, 2013.

[24] Lipinski CA. Drug-like properties and the causes of poor solubility and poor permeability. J Pharmacol Toxicol Methods 2008; 44: 235-49.

[25] Karthick J, Praveen Kumar PK. In-silico analysis of targeted drug delivery to hepatic cells using lipidnano-particles to treat liver diseases. Asian J Pharm Tech 2013; 3: 93-7.

[26] Zakharov AV, Lagunin AA, Filimonov DA, et al. Quantitative prediction of antitarget interaction profiles for chemical compounds. Chem Res Toxicol 2012; 25: 2378-85.

[27] Masand VH, Mahajana DT, PatilaKN, et al. General Unrestricted Structure Activity Relationships based evaluation of quinoxaline derivatives as potential influenza NS1A protein inhibitors. Der Pharma Chemica 2011; 3: 517-25.

[28] Sakakura C, Hagiwara A, Fukuda K, et al. Possible involvement of inositol 1,4,5-trisphosphate receptor type 3 (IP3R3) in the 
peritoneal dissemination of gastric cancers. Anticancer Res 2003; 23: 3691-7.

[29] Berridge MJ. Inositol trisphosphate and calcium signaling. Nature 1993; 361: 315-25.

[30] Pearson G, Robinson F, Beers Gibson T et al. Mitogen-activated protein (MAP) kinase pathways: regulation and physiological functions". Endocr Rev 2001; 22(2): 153-83.

[31] Hilger RA, Scheulen ME, Strumberg D. The Ras-Raf-MEK-ERK pathway in the treatment of cancer". Onkologie 2002; 25(6): 511-8.

[32] Sebolt-Leopold JS. Advances in the development of cancer therapeutics directed against the RAS-mitogen-activated protein kinase pathway. Clin Cancer Res 2008; 14(12): 3651-6.

[33] McConathy J,Owens MJ. Stereochemistry in drug action. Prim Care Companion J Clin Psychiatry 2003; 5: 703.

[34] Wallace AC, Laskowski RA,Thornton JM. LIGPLOT: a program to generate schematic diagrams of protein-ligand interactions. Protein Eng 1992; 8: 127-34.

[35] Friesner RA, Murphyv RB, Repasky MP, et al. Extra precision glide:docking and scoring incorporating a model of hydrophobic enclosurefor protein-ligand complexes. J Med Chem 2006; 49: 6177-96.

[36] Yadava U, Singh M, Roychoudhury M. Pyrazolo[3,4-d]pyrimidines as inhibitor of anti-coagulation and inflammation activities of phospholipase $\mathrm{A}_{2}$ : insight from molecular docking studies. J Biol Phys 2013; 7: 10867-967.

[37] The Chemistry of amino acids. The Biology Project, Department of Biochemistry and Molecular Physics, The University of Arizona. 2004.

[38] Technetium-99m. Fact Sheet. 2002; vol. 2, pp. 320-83.

[39] Ganesan A. The impact of natural products upon modern drug discovery. Curr Opin Chem Biol 2008; 12: 306-17.

[40] Dehmer M, Varuza K, Bonchev D. Statistical Modelling of Molecular Descriptors in QSAR/QSPR. In: Yee LC, Wei YC, Eds. Current Modeling Methods Used in QSAR/QSPR. Wiley-Black well: US 2012; vol. 2.

(C) Joy and Balaji; Licensee Bentham Open.

This is an open access article licensed under the terms of the (https://creativecommons.org/licenses/by/4.0/legalcode), which permits unrestricted, noncommercial use, distribution and reproduction in any medium, provided the work is properly cited. 